\title{
Improved Disturbance Observer of Maximum Power Point Tracking in PV Cells
}

\author{
Liao Hui ${ }^{1,2}$, Gong Yongzhen ${ }^{1}$, Huang Chonglin ${ }^{1}$, Li Shidong ${ }^{1}$ \\ ${ }^{1}$ Guangdong University of Petrochemical Technology, Maoming, 525000 \\ ${ }^{2}$ Development center of technology for fruit \& vegetables storage and processing engineering, \\ Maoming, 525000
}

Keywords: Disturbance observation strategy; PV power generation; maximum power point

Abstract: Aiming at the low output power of PV cells, a Photovoltaic (PV) cell model of photoelectric conversion method is proposed, and the maximum power point (MPP) of PV power generation system was in-depth studied, due to the instability of the output power of PV cells, an improved disturbance observation (IDO) scheme for Maximum Power Point Tracking (MPPT) is put forward, and the IDO for in-depth simulation analysis is proposed in this paper.

\section{Introduction}

Solar energy resources are renewable energy, clean and pollution-free, the use of solar energy has been the focus of researchers [1-3], the intensity of photoelectric conversion efficiency is of great influence affecting the development of PV power generation, in order to make the PV panels strong illumination, scholars have taken a large number of studies on it, such as the biaxial solar automatic tracking system can be achieved on different sun angle tracking, which improved PV panels light efficiency [4,5], however, when it is fixed in the light intensity, the maximum photoelectric conversion efficiency is the most important parameter, in order to achieve a high conversion efficiency, the MPPT of PV is commonly used research method, now commonly methods are disturbance observation and incremental conductance [6,7].

When the light intensity changes little, the control strategy upper is easy to control, and it can get a better photoelectric conversion efficiency, however, when the light insensitive changes suddenly, the tracking control efficiency of the battery board is very different [8]. In order to achieve stable output the maximum power of PV panels, the disturbance observation method based on improved rule is put forward, the boost circuit was used in the power tracking, the simulation model of PV system is built, and the simulation experiments are made to verify the rules.

\section{Equivalent model of PV power generation system}

The equivalent circuit diagram of PV cells and its loads are shown in Fig.1, which is affected by the external light intensity and the surface temperature of the PV cell, and the output current of the $\mathrm{PV}$ cell can be built $\mathrm{I}=\mathrm{f}(\mathrm{S}, \mathrm{V}, \mathrm{T})$. According to the circuit equivalent principle, the ideal equivalent model of PV cells can be obtained; the expression of PV cells is [1]:

$$
I=I_{p h}-I_{o}\left\{\exp \left[\frac{q\left(V+I R_{s}\right)}{A K t}\right]-1\right\}-\frac{U+I R_{s}}{R_{s h}}
$$

Where: $I_{\mathrm{ph}}$ - photocurrent (a); $I_{0}$-reverse saturation current (a); $q$-electronic charge $(1.6 \times$ $\left.10^{19} \mathrm{C}\right) ; K$ - Boltzmann constant $\left(1.38 * 10^{-23} \mathrm{~J} / \mathrm{K}\right) ; t$ - the absolute temperature $(\mathrm{k}), A$-diode factor; $R_{\mathrm{S}^{-}}$ series resistance $(\Omega) ; R_{\text {sh }}$-parallel resistance $(\Omega) ; I$-current output (A); $U$ - output voltage $(\mathrm{V})$. 


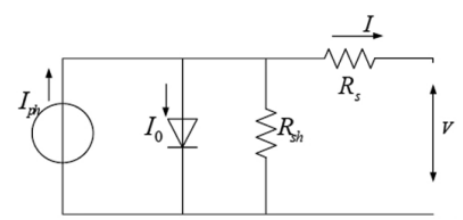

Fig.1 Equivalent circuit diagram of PV cells

To achieve the different power output of DC circuit, the boost circuit can changes the duty ratio to acquire the appropriate voltage, and then it will achieve the regulation of output power, therefore, the PV battery system, has the PV maximum power output by using boost circuit to regulate the output voltage, the photoelectric output power, the output current and the duty ratio of the PV system can be express as:

$$
P_{p v}=I_{L}\left[I_{p v} \eta(1-D)^{2} R_{L}\right]-I_{0}\left[I_{p v} \eta(1-D)^{2} R_{L}\right]\left\{\exp \left[\frac{I_{p v} \eta(1-D)^{2} R_{L}}{A K T}\right]-1\right\}
$$

Where Ppv-PV cell output power; $\eta$-System efficiency; RL-Output load; D-Main circuit switch duty cycle。

\section{MPPT algorithm}

\subsection{MPPT tracking principle}

In the slight change time $d t$, PV battery and its load can be approximated by a linear circuit and equivalent load, $V_{\mathrm{i}}$ is the output voltage in micro time $d t, I$ is its corresponding output current, $R_{\mathrm{i}}$ is the resistance in the micro variable time and $R_{0}$ is the load, then the output power in time $d_{\mathrm{t}}$ is:

$$
d p / d R_{0}=V_{\mathrm{i}}^{*}\left(R_{\mathrm{i}}-R_{0} /\left(R_{\mathrm{i}}+R_{0}\right)^{2}\right.
$$

From type (3), when $R_{\mathrm{i}}=R_{0}$, the output power $p$ has the maximum value, that is to say, to consists of linear components, the independent source is composed of a linear circuit, if the internal resistance is equal to the load resistance value, then the power supply can be the maximum power output, the maximum power point tracking the basic principle of the control method is to control the load resistance and PV cells transiently with equal resistance, the PV battery will work at the maximum power point.

\subsection{MPPT control based on disturbance observation strategy}

The current power $P_{1}$ can be obtained by measuring the PV cell output voltage and current, the next moment output power $P_{2}$ can be calculated according to the measurement of voltage and current, then the variable power is $P_{1}-P_{2}$ between the two times, when the variable power were subtracted, then the voltage is increased, or it will decreased, by taking this approach, we will get the maximum output power $P_{\mathrm{m}}$, as for the voltage is increased or decreased, which is determined by powers of the different time.

\section{Simulation Analysis}

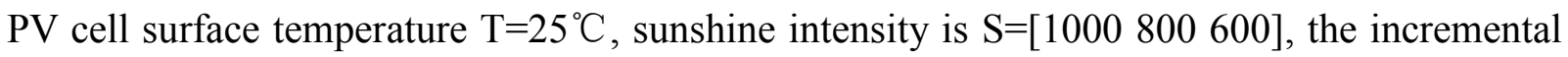
duty ratio is $\mathrm{DD}=0.001$, as can be seen from Fig. 6 and Fig. 7 , in accounting for empty than $\mathrm{D}=0.001$, the vibration amplitude of PV output power is larger; especially it is more apparent under strong 
light, it is due to the maximum output power under the control the disturbance observation method, at this time, due to the PV system in the choice of different output voltage in a short time, and leads to the voltage instability, from Fig. 1 can be seen, voltage fluctuations are relatively large, PV cells eventually led to the fluctuation of output power is great, the power fluctuation leads to reduced the power quality, which affects the service life of the PV power generation system.

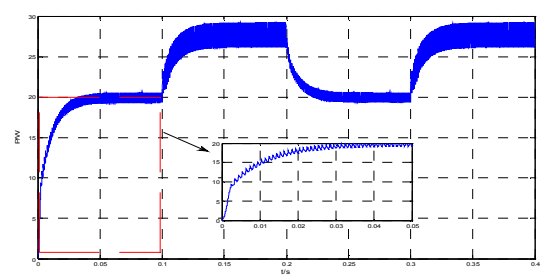

Fig.1 Output power of different light intensity

In order to overcome the shortcomings of disturbance observation method, it need the corresponding improvement of the disturbance observation method, in this method, the four variables $\Delta \mathrm{P}_{\mathrm{pv}}(\mathrm{k}) 、 \Delta \mathrm{P}_{\mathrm{pv}}(\mathrm{k}-1) 、 \Delta \mathrm{V}_{\mathrm{pv}-\mathrm{ref}}(\mathrm{k}) 、 \Delta \mathrm{V}_{\mathrm{pv}-\mathrm{ref}}(\mathrm{k}-1)$ are the input in the method, the next moment duty ratio is the output, its block diagram as shown in the Fig.2.

The improved disturbance observation method is shown in Fig.2.

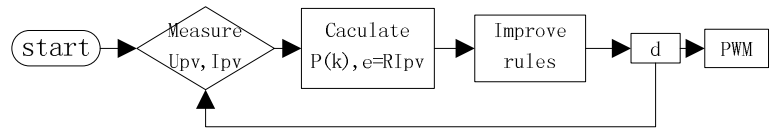

Fig.2 Block diagram of improved rule

PV cell surface temperature $\mathrm{T}=25^{\circ} \mathrm{C}$, the intensity of sunlight $\mathrm{S}=[1000,600,800]$, accounting for the incremental $\mathrm{DD}=0.0001$ when the simulation results as shown in Fig.3.

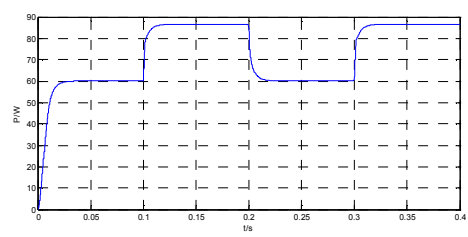

Fig.3 Output power of different light intensity

When the light intensity signal is [500 1000500 1000], from the Fig.10 we can be seen that the power output become relative gentle with little vibration, which did not appear as shown in the fluctuation, the duty ratio of output is a certain degree of restraint, the output relationship between the voltage and power were shown in Fig.4.

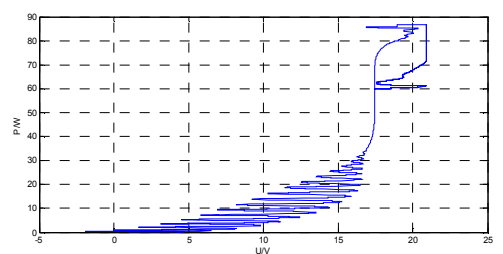

Fig.4 Output power voltage characteristics of different light intensity

\section{Conclusion}

Through the comprehensive analysis results on the simulation of PV, its output power was 
great effected by the light intensity, especially the maximum power point prone to fluctuations when the light changes shapely, MPPT model of PV is based on the boost circuit, which was controlled by the improved DO strategy, the results showed that the output power was in the steady state in light intensity change process, which showed that improved DO strategy for maximum power tracking had a good quality, and it was in line with the requirements of the PV conversion, on the other hand, whether changing the duty ratio for MPPT is good to achieve the optimal or not, we need to the further researches.

\section{Acknowledgement}

This paper is supported by the science and technology project of Guangdong province (2014A010106033); the natural science foundation of Guangdong Province, the startup project of

Guangdong province (2014A030310376); Guangdong Province Ordinary University Youth Innovative Talents Project (2014KQNCX201, 631051); The PhD Startup Fund of Natural Science Foundation of Guangdong Province (2014A030310376).

\section{References}

[1] Nivedita Dasgupta, Ashish Pandey, Ashok K Mukerjee. Voltage-sensing-based PV MPPT with improved tracking and drift avoidance capabilities[J]. Solar Energy Materials \& Solar Cells, 2008, 92: 1552-1558.

[2] Fayrouz Dkhichi; Benyounes Oukarfi; Youssef El Kouar; David Ouoba; Abderrahim Fakkar. Neural network based integration of MPPT and diagnosis of degradation for PV module[J]. Optical and Quantum Electronics, 2016 (48), 2:105-117.

[3] Dkhichi, F., Oukarfi, B., Fakkar, A., Belbounaguia, N.: Parameter identification of solar cell model using Levenberg-Marquardt algorithm combined with simulated annealing. Sol. Energy 110, 781-788 (2014)

[4] Raúl Gregor;Yoshihiko Takase;Jorge Rodas;Leonardo Carreras;Derlis Gregor;Andrés López. Biaxial Solar Tracking System Based on the MPPT Approach Integrating ICTs for PV Applications[J]. International Journal of Photoenergy, 2015,Vol.2015.

[5] Chao Liu;Jing Hui. Research on Physical MPPT of PV Array System Based on Image Processing[J]. Applied Mechanics and Materials, 2013, Vol.321-324: 1138-1144 .

[6] Akhil Gupta;Saurabh Chanana;Tilak Thakur. THD reduction with reactive power compensation for fuzzy logic DVR based solar PV grid connected system[J]. Frontiers in Energy, 2014, Vol.8, No.4:464-479.

[7] SACHIN VRAJLAL RAJANI;VIVEK J PANDYA, Simulation and comparison of perturb and observe and incremental conductance MPPT algorithms for solar energy system connected to grid[J]. Sadhana, 2015, Vol.40, No.1 :139-153.

[8] Shahin Azali(1);Mansour Sheikhan(1) Intelligent control of PV system using BPSO-GSA-optimized neural network and fuzzy-based PID for maximum power point tracking[J], Applied Intelligence, , 2016 ,Vol.44, No.1 :88-110 